\title{
ChemComm
}

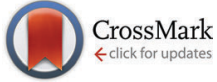

Cite this: Chem. Commun., 2015, 51,6183

Received 13th February 2015 Accepted 2nd March 2015

DOI: $10.1039 / c 5 c c 01368 b$

www.rsc.org/chemcomm

\section{Combination of automated solid-phase and enzymatic oligosaccharide synthesis provides access to $\alpha(2,3)$-sialylated glycans $\dagger$}

\author{
Richard J. Fair, ${ }^{a}$ Heung Sik Hahm ${ }^{a b}$ and Peter H. Seeberger ${ }^{\star a b}$
}

\section{A synthetic strategy combining automated solid-phase chemical synthesis and enzymatic sialylation was developed to access $\alpha(2,3)$-sialylated glycans.}

$\mathrm{N}$-Acetyl-neuraminic acid (Neu5Ac) is the most studied among the over 50 sialic acids described to date and is a component of many glycans of biological relevance. $\alpha(2,6)$-Sialylated and $\alpha(2,3)$ silylated glycans are predominantly found in nature. ${ }^{1-3}$ Sialylated glycans on the cell surface regulate various cellular functions ${ }^{4}$ and are linked to a host of extracellular recognition events. ${ }^{5,6}$ Sialic acid containing glycans are associated with many cancers, ${ }^{7-9}$ autoimmune disorders, ${ }^{10}$ and diabetes ${ }^{11}$ but are also exploited by pathogenic organisms including trypanosomes, ${ }^{12}$ bacteria, ${ }^{13}$ and viruses. ${ }^{14}$ Biological studies greatly benefit from the availability of defined glycans as molecular probes.

Sialylated oligosaccharides have been a challenge for synthetic chemists since no participating group can be placed at the neighboring C-3 position and next to the sterically hindered, quaternary anomeric center is an electron withdrawing carbonyl that diminishes the reactivity. Significant progress has been made in developing efficient chemical sialylation reactions but glycosylation efficiencies for these linkages still remain significantly lower than those obtained for other couplings. ${ }^{2,15,16}$ The automated assembly of glycans on solid support benefits from mass action of the glycosylating agent and has resulted in the rapid assembly of ever more complex glycans. ${ }^{16,17}$ However, the automated assembly of sialylated glycans has been challenging. Sialic acid-galactose disaccharide building blocks were used to produce $\alpha(2,3)$ - and $\alpha(2,6)$-sialylated glycans by automated solid-phase synthesis. ${ }^{18}$

\footnotetext{
${ }^{a}$ Department of Biomolecular Systems, Max-Planck-Institute of Colloids and Interfaces, Am Mühlenberg 1, 14476 Potsdam, Germany.

E-mail: peter.seeberger@mpikg.mpg.de; Fax: +49 30 838-59302; Tel: $+4930838-59301$

${ }^{b}$ Freie Universität Berlin, Institute of Chemistry and Biochemistry, Arnimallee 22, 14195 Berlin, Germany

$\dagger$ Electronic supplementary information (ESI) available: Experimental procedures, characterization data, NMR spectra, and analytical HPLC traces. See DOI: $10.1039 / \mathrm{c} 5 \mathrm{cc} 01368 \mathrm{~b}$
}

The use of disaccharide building blocks is not ideal within the logic framework of glycan assembly based on monosaccharide building blocks. More recently, a sialic acid monosaccharide building block proved useful in producing $\alpha(2,6)$-sialylated glycans. ${ }^{19} \alpha(2,3)$-Silylated glycans were formed in low yields $(<20 \%)$ using this method.

To address the challenge that could not be met with chemical means alone, the combination of automated glycan assembly and enzymatic glycan synthesis, two complementary techniques, might offer a solution. Here, we demonstrate that glycans assembled by automated synthesis can be used as scaffolds for enzymatic elaboration to access the desired sialylated glycans. Sialyltransferases transfer sialic acids from activated cytodine monophosphate (CMP)-sialic acids to oligosaccharide substrates. ${ }^{1}$ Bacterial sialyltransferases have been reliable tools to efficiently and selectively install desired sialic acids ${ }^{2,20}$ even on gram scale. ${ }^{21}$ By combining the power of automated glycan assembly to prepare the glycan backbone with the efficiency and selectivity of glycan sialylation, this strategy combines the advantages inherent to both methods for the rapid production sialylated glycans.

Five oligosaccahrides $\mathrm{GM}_{3}(\mathbf{1}), \mathrm{GM}_{1} \mathrm{~b}\left(\operatorname{cisGM}_{1}, 2\right)$, sialyl $\mathrm{LC}_{4}(\mathbf{3})$, SPG (sialyl $\left.n \mathrm{LC}_{4}, \mathbf{4}\right)$, and SLPG $\left(n \mathrm{HM}_{1}, 5\right)$ (Fig. 1) were selected to explore the combination of automated glycan assembly and enzymatic sialylation. These sialosides are structurally similar as they have linear, non-fucosylated backbones and terminal sialic acids since the sialyltransferase used for these proof-of-principle studies, a truncated Pasturella multocida sialyltransferase 1 (PmST1), operates on such linear structures.

$\alpha(2,3)$-Sialyltransferases glycosylate terminal galactose residues and moieties immediately next to the galactose effect the sialylation efficiency. ${ }^{22}$ To evaluate the influence of the nearest neighbor of galactose on the enzymatic reactions, different sugars and linkages next to the galactose residue were explored. The target molecules are either tumor-associated carbohydrate antigens (TACAs) $(\mathbf{1}, \mathbf{2}, \mathbf{4}),^{7,23-25}$ associated with autoimmune disorders $(\mathbf{1}, \mathbf{2}, \mathbf{4}, \mathbf{5}),{ }^{10,26-28}$ or exploited by pathogens $(\mathbf{1}, \mathbf{4}) .^{13,29,30}$

The synthetic strategy, exemplified for the synthesis of $\mathrm{GM}_{1} \mathrm{~b}(2)$ (Scheme 1) relies on the automated solid phase assembly of the glycan backbone (11) using thioglycoside building blocks (6-9) 

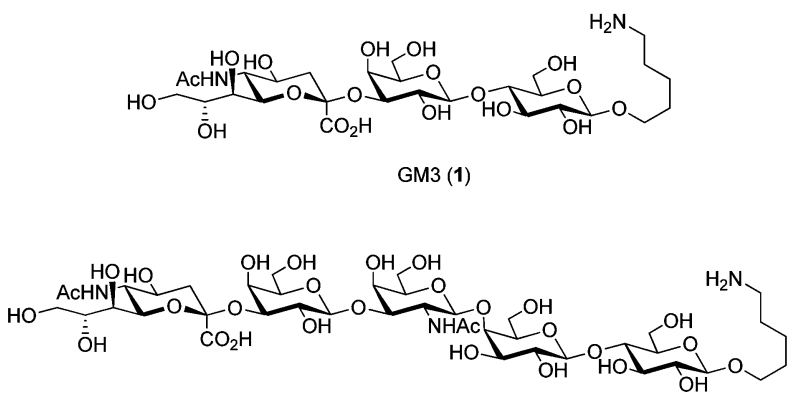

GM1b (cisGM1, 2)
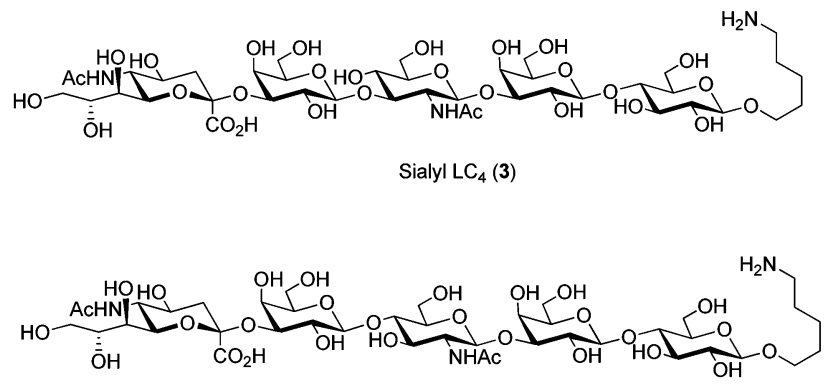

SPG (Sialyl nLC 4,4 )

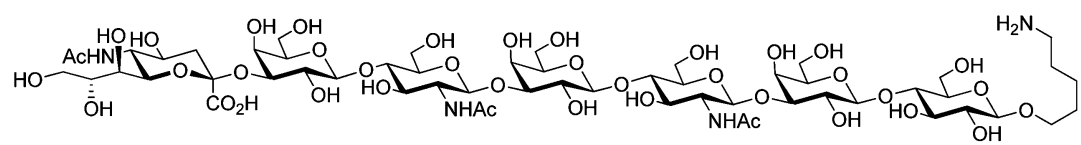

SLPG (nHM1, 5)

Fig. $1 \alpha(2,3)$-Sialic acid containing target glycans.

A)

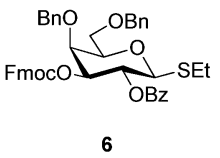

6

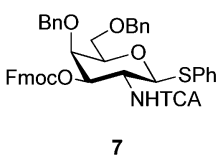

7

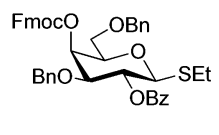

8

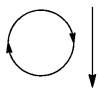

D)

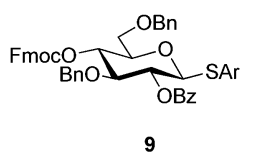

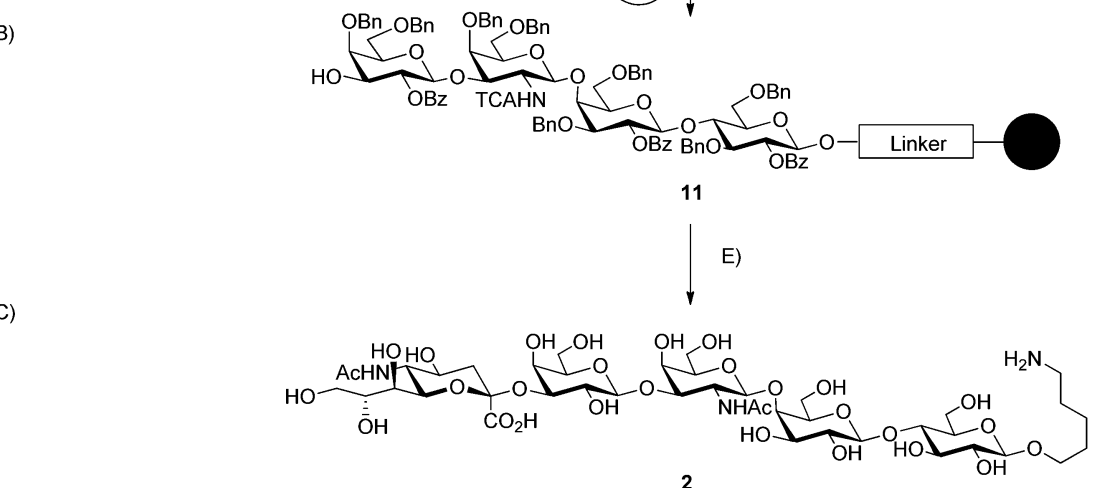

B)

C)

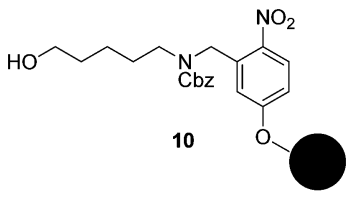

Scheme 1 Automated glycan assembly synthetic strategy illustrated for $G_{1} b$ (2). (A) Thioglycoside building blocks and photo-cleavable resin; (B) fully protected, resin-bound glycoside; (C) $\alpha(2,3)$-sialylated glycoside; (D) automated steps: (1) glycosylation (NIS, TfOH, DCM, Dioxane), (2) Fmoc deprotection (TEA, DMF), (3) acidic wash (TMSOTf, DCM); (E) post-automation steps: (1) photo-cleavage (hv, DCM), (2) methanolysis ( $\mathrm{NaOMe,} \mathrm{MeOH,}$ DCM), (3) hydrogenolysis (Pd/C, $\mathrm{H}_{2}, \mathrm{MeOH}, \mathrm{H}_{2} \mathrm{O}, \mathrm{AcOH}$ ), (4) sialylation ( $\alpha(2,3)$-sialyltransferase, CMP-Neu5Ac, alkaline phosphatase, Tris- $\mathrm{HCl}$ buffer).

and resin appended with a photo-cleavable linker $(\mathbf{1 0})^{31}$ through successive cycles of glycosylation. All reaction steps including removal of the fluorenylmethloxycarbonyl (Fmoc) temporary protecting group and acidic washes are carried out on an automated synthesizer. $^{32}$ Building blocks were activated using $\mathrm{N}$-iodosuccinimide (NIS) and triflic acid (TfOH) and two couplings using each 4.4 equivalents of building block in all cases except for SLPG (5) where five equivalents of building block per cycle were used. Building blocks $(\mathbf{6}, \mathbf{8}, \mathbf{9}, \mathrm{S} 3-\mathrm{S} 5$, ESI $\dagger$ ) have been developed previously $^{33-35}$ and were known to couple efficiently and selectively. Fmoc protecting groups were removed by exposure to a solution of triethylamine (TEA) (20\% in dimethylformamide (DMF)). An acid wash with trimethylsilyltriflate (TMSOTf) follows to ensure the removal of base prior to the introduction of the next building block. UV irradiation of the resin in a continuous flow device afforded fully protected oligosaccharides. ${ }^{31}$ Yields for protected glycosides were high with only very small quantities of deletion sequences observed by analytical HPLC. Overall yields following HPLC purification ranged from $36 \%$ to $46 \%$ with the number of automated steps ranging from four steps for the disaccharide precursor to $\mathrm{GM}_{3}$ to twelve steps for the hexasaccharide precursor of SLPG (Table 1).

All remaining protective groups were removed to obtain completely deprotected oligosaccharides. Benzoyl esters were 
Table 1 Yields for automated synthesis, global deprotection, and sialylation for target glycans ${ }^{a}$

\begin{tabular}{llll}
\hline Target glycan & $\begin{array}{l}\text { Automation } \\
\text { (overall) }^{b}\end{array}$ & $\begin{array}{l}\text { Global } \\
\text { deprotection }\end{array}$ & Sialylation $^{c}$ \\
\hline $\mathrm{GM}_{3}(1)$ & 42 & 82 & 87 \\
$\mathrm{GM}_{1} \mathrm{~b}(2)$ & 46 & 91 & 78 \\
$\mathrm{SLC}_{4}(3)$ & 36 & 83 & 79 \\
SPG (4) & 44 & 86 & 87 \\
SLPG (5) & 37 & 78 & 89
\end{tabular}

${ }^{a}$ All yields given as \% values. ${ }^{b}$ Yield of protected glycan following photo-cleavage from resin and HPLC purification as determined based on resin loading. ${ }^{c}$ Yield of deprotected glycan following methanolysis, hydrogenolysis, and HPLC purification. ${ }^{d}$ Yield of enzymatic sialylation following HPLC purificaiton.

removed by methanolysis using a solution of sodium methoxide (NaOMe) in methanol and dichloromethane (DCM) at $40{ }^{\circ} \mathrm{C}$. Subsequent hydrogenolysis of benzyl ethers and the carboxybenzyl (Cbz) carbamate with concurrent reduction of trichloroacetyl (TCA) groups was achieved upon exposure to $45 \mathrm{psi}$ hydrogen with a $\mathrm{Pd} / \mathrm{C}$ catalyst in a methanol, water, and acetic acid solution. Following global deprotection, the products were HPLC purified to yield substrates for the $\alpha(2,3)$-sialyltransferase. The deprotection steps yielded $78-91 \%$ of the desired glycans over two steps (Table 1). The free glycans are appended with an amine functionalized linker that serves as a convenient handle for ligation to microarrays or carrier proteins used in vaccine conjugates.

With several oligosaccharides in hand, a truncated $\alpha(2,3)$ sialyltransferase from Pasturella multocida (PmST1) was employed for enzymatic sialylation. This commercially available enzyme has a broad substrate specificity and has been used successfully in enzymatic syntheses. ${ }^{22}$

The sialylation reactions employed $\alpha(2,3)$-sialyltransferase, CMP-Neu5Ac, and an alkaline phosphatase that serves to dephosphorylate the CMP byproduct of the reaction. Reactions proceeded in a Tris-HCl buffer at $\mathrm{pH} 8.0$ at $37{ }^{\circ} \mathrm{C}$ with high conversion ( $>95 \%$ as determined by analytical HPLC) for all substrates with 1,4-linked terminal galactose residues $\left(\mathrm{GM}_{3}, \mathrm{SPG}\right.$, and SLPG precursors) using 1.1 equivalents of CMP-Neu5Ac and $30 \mathrm{mU}$ sialyltransferase per mmol substrate. Sialylation was less efficient for substrates with 1,3-linked galactoses $\left(\mathrm{GM}_{1} \mathrm{~b}\right.$ and $\mathrm{sLC}_{4}$ precursors), however. To achieve high conversion (86\%) in the case of $\mathrm{SLC}_{4}$ more enzyme was necessary $(120 \mathrm{mU}$ sialyltransferase per mmol substrate). In the case of $\mathrm{GM}_{1} \mathrm{~b}$, high conversion $(87 \%)$, required more enzyme and four equivalents of CMP-Neu5Ac. Isolated yields, following HPLC purification of the target sialosides ranged from $78-89 \%$ (Table 1 ).

Automated glycan assembly and enzymatic synthesis were combined to produce five $\alpha(2,3)$-sialylated glycans. Solid-phase chemistry is used for the rapid and high yielding production of the glycan backbones using just a few building blocks, while the sialyltransferase is used for high yielding and highly regioand stereoselective sialylation. The combination of automated and enzymatic glycosylations is expected to be of general utility. Future work will seek to apply this approach to other enzymes.
We thank the Max-Planck Society and the European Research Council (ERC Advanced Grant AUTOHEPARIN to PHS) for generous financial support.

\section{Notes and references}

1 Essentials of Glycobiology, ed. A. Varki, R. Cummings, J. Esko, H. Freeze, G. Hart and J. Martht, Cold Spring Harbor Laboratory Press, Cold Spring Harbor, 2009.

2 X. Chen and A. Varki, ACS Chem. Biol., 2010, 5, 164-176.

3 D. B. Werz, R. Ranzinger, S. Herget, A. Adibekian, C.-W. von der Lieth and P. H. Seeberger, ACS Chem. Biol., 2007, 2, 685-691.

4 K. Furukawa, K. Hamamura, W. Aixinjueluo and K. Furukawa, Ann. N. Y. Acad. Sci., 2006, 1086, 185-198.

5 I. Bucior and M. M. Burger, Curr. Opin. Struct. Biol., 2004, 14, 631-637.

6 R. Schauer, Curr. Opin. Struct. Biol., 2009, 19, 507-514.

7 S. I. Hakomori and Y. Zhang, Chem. Biol., 1997, 4, 97-104.

8 R. D. Astronomo and D. R. Burton, Nat. Rev. Drug Discovery, 2010, 9, 308-324.

9 M. M. Fuster and J. D. Esko, Nat. Rev. Cancer, 2005, 5, 526-542.

10 R. A. C. Hughes and D. R. Cornblath, Lancet, 2005, 366, 1653-1666.

11 E. Cabrera-Rode, O. Diaz-Horta, L. E. Fernandez, A. Carr, G. Marquina, O. Valiente, R. M. Gonzalez-Suarez and A. Uriarte, Autoimmunity, 1995, 20, 145-151.

12 R. Schauer and J. P. Kamerling, ChemBioChem, 2011, 12, 2246-2264.

13 C. S. Berenson, K. B. Sayles, J. Huang, V. N. Reinhold, M. A. Garlipp and H. C. Yohe, FEMS Immunol. Med. Microbiol., 2005, 45, 171-182.

14 J. Fantini, D. Hammache, G. Pieroni and N. Yahi, Glycoconjugate J., 2000, 17, 199-204.

15 M. J. Kiefel and M. von Itzstein, Chem. Rev., 2002, 102, 471-490.

16 C.-H. Hsu, S.-C. Hung, C.-Y. Wu and C.-H. Wong, Angew. Chem., Int. Ed., 2011, 50, 11872-11923.

17 P. H. Seeberger, Chem. Soc. Rev., 2008, 37, 19-28.

18 D. Esposito, M. Hurevich, B. Castagner, C.-C. Wang and P. H. Seeberger, Beilstein J. Org. Chem., 2012, 8, 1601-1609.

19 C.-H. Lai, H. S. Hahm, C.-F. Liang and P. H. Seeberger, submitted.

20 R. M. Schmaltz, S. R. Hanson and C.-H. Wong, Chem. Rev., 2011, 111, 4259-4307.

21 S. Fort, L. Birikaki, M. P. Dubois, T. Antoine, E. Samain and H. Driguez, Chem. Commun., 2005, 2558-2560.

22 H. Yu, H. Chokhawala, R. Karpel, H. Yu, B. Wu, J. Zhang, Y. Zhang, Q. Jia and X. Chen, J. Am. Chem. Soc., 2005, 127, 17618-17619.

23 M. H. Ravindranath, S. Muthugounder, N. Presser, S. R. Selvan, A. D. Santin, S. Bellone, T. S. Saravanan and D. L. Morton, Biochem. Biophys. Res. Commun., 2007, 353, 251-258.

24 Z. Wang, L. Wen, X. Ma, Z. Chen, Y. Yu, J. Zhu, Y. Wang, Z. Liu, H. Liu, D. Wu, D. Zhou and Y. Li, Glycobiology, 2012, 22, 930-938.

25 Y. Kawaguchi, Y. Miyamoto, T. Inoue and Y. Kaneda, Int. J. Cancer, 2009, 124, 2478-2487.

26 Y. Tsukuda, N. Iwasaki, N. Seito, M. Kanayama, N. Fujitani, Y. Shinohara, Y. Kasahara, T. Onodera, K. Suzuki, T. Asano, A. Minami and T. Yamashita, PLoS One, 2012, 7, e40136.

27 A. Ikeda, A. Komatsuzaki, T. Kasama, S. Handa and T. Taki, Biochim. Biophys. Acta, 2000, 81-90.

28 N. Yuki, Y. Tagawa and S. Handa, J. Neuroimmunol., 1996, 70, 1-6.

29 S. S. Rawat, S. A. Gallo, J. Eaton, T. D. Martin, S. Ablan, V. N. KewalRamani, J. M. Wang, R. Blumenthal and A. Puri, J. Virol., 2004, 78, $7360-7368$.

30 G. Nyberg, N. Stromberg, A. Jonsson, K. A. Karlsson and S. Normark, Infect. Immun., 1990, 58, 2555-2563.

31 S. Eller, M. Collot, J. Yin, H. S. Hahm and P. H. Seeberger, Angew. Chem., Int. Ed., 2013, 52, 5858-5861.

32 O. J. Plante, E. R. Palmacci and P. H. Seeberger, Science, 2001, 291, 1523-1527.

33 H. S. Hahm, M. Schlegel, M. Hurevich, S. Eller and P. H. Seeberger, in preparation.

34 O. Calin, S. Eller, H. S. Hahm and P. H. Seeberger, Chem. - Eur. J., 2013, 19, 3995-4002.

35 L. Kröck, D. Esposito, B. Castagner, C. C. Wang, P. Bindschädler and P. H. Seeberger, Chem. Sci., 2012, 3, 1617-1622. 